\title{
Zum Tode von Nikos Poulantzas
}

\section{Nikos Poulantzas war unser Freund.}

Seit vielen Jahren haben wir uns immer wieder mit ihm im Kampf für Werte zusammengefunden, die wir ganz einfach für das Salz der Erde halten - auch wenn wir nicht jede einzelne der von ihm vertretenen Thesen geteilt haben. Einig waren wir uns mit ihm in seinem unwiderruflichen Eintreten für die Sache der Unterdrückten und Ausgestoßenen dieser Welt. Wir waren wie er davon überzeugt, daß sich aus diesem Eintreten die unausweichliche Notwendigkeit des kritischen Gebrauchs der Vernunft als Bedingung wirksamen Handelns gegen die Kette von Abhängigkeit und Unterdrückung begründet.

Nikos Poulantzas war Grieche, organisierter Kommunist und Antistalinist. Damit kannte er die vielen Gesichter, die die politische Sklaverei heute trägt. Er kannte den Faschismus, der lange Jahre hindurch sein Vaterland in eine Hölle verwandelte, und hat mit unvergleichlicher Treffsicherheit seinen Erfolg in der Krise der 30er Jahre in Italien und Deutschland analysiert (,Faschismus und Diktatur") und die Bedingungen dafür aufgezeigt, daß er sich heute in den Mittelmeerländern auflösen und in demokratische Herrschaftsformen übergehen mußte (,Die Krise der Diktaturen"). Dazu gehören vor allem die neuen Formen der Unterwerfung unter das Kapitalverhältnis, die mit der Entwicklung der modernen Industriegesellschaft und des neokolonialen Imperialismus entstanden sind, wie Nikos Poulantzas sie in „Klassen im Kapitalismus

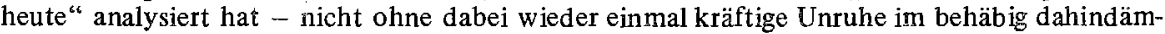
mernden Tümpel von liebgewordenen Vorurteilen zu stiften, wie ihn auch die Linke hegt.

Es hieße aber sein Denken verkürzen und verflachen, es um seinen wesentlichen, harten Kern zu bringen, wenn wir den Zusammenhang wegließen, in dem diese Analysen standen: Sein gesamtes Denken drehte sich um die Analyse der Formen des modernen Staates, worin er sowohl die Achillesferse des Marxismus sah wie auch die dringendste Aufgabe, vor der heute ein Intellektueller steht, der diese Bezeichnung verdient. Ist es der Sozialstaat mit seinen beruhigend bemutternden Zügen, wie es uns diejenigen Sozialisten versichern, denen es um nichts weiter geht, als um die Verwaltung der Macht? Ist es der Leviathan, das Schreckgespenst von AntiEtatisten sämtlicher Spielarten? Ist es der Staat-des-Volkes-in-seiner-Gesamíheit, von dem die ,weich" gewordenen Totalitaristen schwärmen? Nikos Poulantzas hat sich keiner dieser Klischeevorstellungen, dieser falschen Entschuldigungen für Unwissenheit und Irrtum, angeschlossen; er zog es vor, die allmählichen Veränderungen der Lage genau $\mathrm{zu}$ beobachten. Angesichts des sprunghaften Anwachsens der autoritären Entwicklungsmöglichkeiten im Kontext eines Kapitalismus in der Krise - das er in der letzten Zeit seines Lebens immer besorgter verfolgte -- und angesichts der Modernisierung des Instrumentariums, über das, die da oben ${ }^{6}$ verfügen, galt seine besondere Sorge dem Veralten der Gegen-Mittel, über die, wir hier unten' verfügen. Sein letzter Artikel trug nicht zufällig den Titel ,Die Krise der Parteien“. Es muß aber auch ganz deutlich ausgesprochen werden, daß für Nikos Poulantzas nicht nur die hinterhältige Einschränkung der bürgerlichen Freiheiten und der demokratischen Rechte, wie sie sich im Westen vollzieht, ein beständiger Grund für Besorgnis und Angst waren: Daß diese Freiheiten und diese Rechte in der Sphäre des , ,Ieal existierenden Sozialismus" nicht existieren, war für ihn als Kommunisten ein unerträglicher \$kandal, weit mehr als eine bloße Abweichung.

Nikos Poulantzas hat anerkanntermaßen die hölzerne Sprache des ,Historischen Materialismus' gesprengt (was ihn um 1968 einem breiten Publikum bekannt machte, sowohl Stu- 
denten wie aktiven Kollegen und Genossen). In seinem ersten Buch, „Politische Macht und gesellschaftliche Klassen", hat er als einzig mögliche Alternative zum bedrückenden und verdummenden Gegenüber von fortgeschrittenem Liberalismus und zurïckgebliebenem Stalinismus einen Sozialismus entworfen, dessen Grundlage das dialektische Zusammenspiel von Basisdemokratie und neuen Formen der repräsentativen Demokratie bildet, die noch erfunden werden müssen. Dementsprechend hat er bis zum Schluß alle seine Hoffnungen in die Versprechungen gesetzt, für die der Eurokommunismus steht. Es hat jedenfalls nicht an ihm gelegen, wenn diese Versprechungen, die den warmen Grundton seines letzten Buches bilden, nicht gehalten worden sind.

Nikos Poulantzas war nicht etwa nur unser Freund, weil er lebendig, warmherzig und großzügig war, wie es ein Mensch vom Mittelmeer zu sein versteht, auch nicht bloß, weil er ganz allein schon, bis hin zu den homerischen Beschimpfungen, den Mittelpunkt eines ganzen Spektrums der französischen Linken bildete, die sich ja nicht immer durch ihre Risikobereitschaft auszeichnet. Er war unser Freund, weil er ein Mensch voller Widersprüche war, voller Zweifel, immer bereit, sich zu hinterfragen, wenn er das Gefühl hatte, die wirkliche Bewegung zwinge ihn dazu.

Der Jahrmarkt der Eitelkeiten wird und kann weitergehen mit seinen Größen des Showgeschäftes und seinen Profis des Selbstwiderrufs, ohne auch nur eine Pause zu machen. Nikos Poulantzas bleibt für uns unersetzlich, für lange Zeit: Wegen seiner unermüdlichen Neugier gegenüber allen neuen Formen politischen Denkens, wegen seiner unverrückbaren Treue zu den Quellen seines eigenen Denkens - und damit als ein Vorbild intellektueller Rechtschaffenheit in einer Zeit beständiger Widerrufe, die einfach zum Kotzen sind.

(Nikos Poulantzas starb mit 43 Jahren, ohne daß dies jemand erwarten konnte. Das nachfolgende Interview war bereits im Satz, als wir die Nachricht von seinem Tode erhielten. Wir halten es für richtig, statt eines von uns verfaßten Nachrufes den voranstehenden Text seiner Pariser Freunde zu drucken. Unterzeichnet haben ihn Claudine Barret-Kriegel, Christine Buci-Glucksmann, Pierre Birnbaum, Regis Debray, Robert Fossaert, Alain Joxe, Daniel Lindenberg, Didier Motchane, Olivier Duhamel, Jean-Marie Vincent und Henri Weber. Veröffentlicht ist der Text in Le Monde vom 10.10.79, S. 17. Die Übersetzung besorgte F. O. Wolf.)

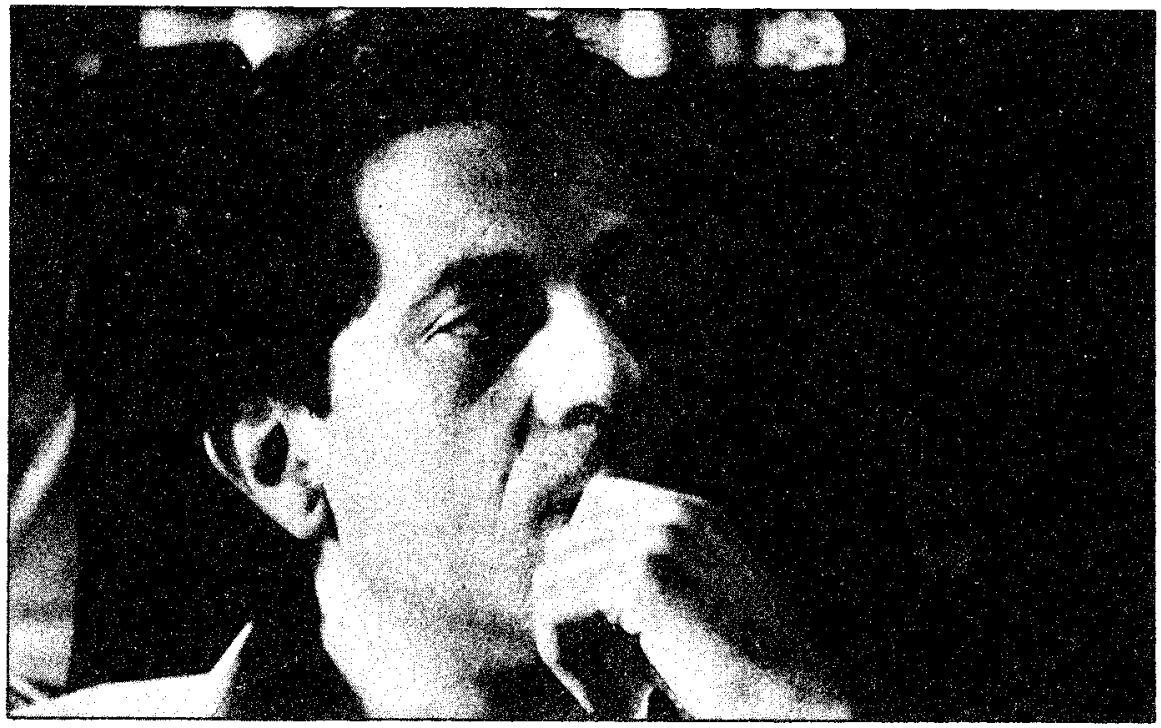

